\title{
Capecitabine and bevacizumab as first-line treatment in elderly patients with metastatic colorectal cancer
}

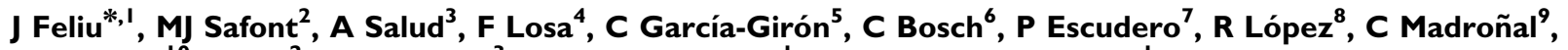 M Bolaños ${ }^{10}$, M Gil', A Llombart ${ }^{3}$, J Castro-Carpeño' and M González-Barón'}

'Medical Oncology Department, Hospital La Paz/Autónoma University School of Medicine. IdiPAZ. RETIC, Po de la Castellana, Madrid 26I- 28046, Spain; ${ }^{2}$ Medical Oncology Department, General Hospital, Avda.Tres Cruces, Valencia s/n - 460 I 4, Spain; ${ }^{3}$ Medical Oncology Department, Arnau Vilanova Hospital, Avda. Alcalde Rovira Roure, Lérida 80 - 25198, Spain; ${ }^{4}$ Medical Oncology Department, L'Hospitalet Hospital, Av. de Josep Molins, Barcelona 29-4 I - 08906, Spain; ${ }^{5}$ General Yagüe Hospital, Avda. del Cid Campeador, $96-09005$ Burgos, Spain; ${ }^{6}$ Medical Oncology Department, Dr Peset Hospital, Avda. Gaspar Aguilar, Valencia 90- 460 I 7, Spain; ${ }^{7}$ Medical Oncology Department, University Lozano Blesa Hospital, Avda. San Juan Bosco, Zaragoza 15- 50009, Spain; ${ }^{8}$ Medical Oncology Department, University Clinic Hospital, Travesía de la Choupana, Santiago de Compostela s/n - 15706 , Spain; ${ }^{9}$ Medical Oncology Department, Corochán Clinic, Cl Buigas, Barcelona 19- 0801 7, Spain; ${ }^{10}$ Medical Oncology Department, San Pedro de Alcántara hospital, Avda. Millán Astray-, Cáceres 10002, Spain

BACKGROUND: The efficacy and safety of capecitabine and bevacizumab in elderly patients with metastatic colorectal cancer (mCRC) considered unsuitable for receiving first-line chemotherapy with an irinotecan or oxaliplatin-based combination were assessed in a phase II, open, multicentre, uncontrolled study.

METHODS: Treatment consisted of capecitabine $1250 \mathrm{mgm}^{-2}$ (or $950 \mathrm{mg} \mathrm{m}^{-2}$ for patients with a creatinine clearance of $\left.30-50 \mathrm{ml} \mathrm{min}^{-1}\right)$ twice daily on days I- 14 and bevacizumab $\left(7.5 \mathrm{mg} \mathrm{kg}^{-1}\right)$ on day I every 3 weeks.

RESULTS: A total of 59 patients aged $\geqslant 70$ years with $\mathrm{mCRC}$ were enrolled. In an intention-to-treat analysis, the overall response rate was 34\%, with $71 \%$ of patients achieving disease control. Median progression-free survival and overall survival were I0.8 months and 18 months, respectively. In all, 32 patients (54\%) had grade 3/4 adverse events (AEs), the most common being hand-foot syndrome (19\%), diarrhoea (9\%) and deep venous thrombosis (7\%). Four patients died because of treatment-related AEs. A relationship was detected between creatinine clearance $\leqslant 50 \mathrm{ml} \mathrm{min}-1$ and the development of non-bevacizumab-related grade $3 / 4$ AEs. The incidence of bevacizumab-associated AEs (hypertension, thromboembolic events and proteinuria) was consistent with that of previous reports in elderly patients.

CONCLUSION: Bevacizumab combined with capecitabine represents a valid therapeutic alternative in elderly patients considered to be unsuitable for receiving polychemotherapy.

British Journal of Cancer (2010) I 02, I468-|473. doi:I0.1038/sj.bjc.6605663 www.bjcancer.com

Published online 27 April 2010

(c) 2010 Cancer Research UK

Keywords: capecitabine; bevacizumab; colorectal neoplasms; neoplasm metastasis; aged

Colorectal cancer (CRC) is the third most frequent tumour in the world, with one million new cases being diagnosed every year (Parkin et al, 2005). Its incidence increases considerably with age, with 18.6 cases per 100000 inhabitants per year among those $<65$ years of age compared with 307.3 cases per 100000 inhabitants per year among those $>65$ years of age (Ries et al, 2002). In Europe, the median age of patients diagnosed with CRC is within the seventh decade of life and $40 \%$ of them are older than 74 years (Gatta et al, 1998). Furthermore, the number of elderly individuals diagnosed with CRC will probably increase in the upcoming years if the demographic forecast on population ageing is taken into account.

\footnotetext{
*Correspondence: Dr J Feliu; E-mail: jfeliu.hulp@salud.madrid.org This study was been presented at the 45th Annual Meeting of American Society of Clinical Oncology (ASCO), Orlando, FL, USA 2009 (abstract 4119); and at the 2008 ASCO Gastrointestinal Cancers Symposium, Orlando (abstract 478).

Received 18 January 2009; revised 24 March 2010; accepted 24 March 2010; published online 27 April 2010
}

Treatment of advanced CRC in the elderly is still a challenge. Elderly individuals constitute a very heterogeneous population with regard to their overall health condition, functional dependence grade, co-morbidities and performance status (PS); hence, the therapeutic decisions in this population must be individualised.

Although most authors agree that the fit elderly patient should receive the same treatment as the youngest (Kohne et al, 2008), there is more disagreement regarding the best treatment for the unfit elderly, as conventional treatments may cause higher toxicity in them. In these cases, some therapeutic guidelines recommend treatment with monotherapy, such as capecitabine or infusions of 5-fluorouracil (5-FU) modulated with leucovorin (LV), with the possible addition of bevacizumab (National Comprehensive Cancer Network (NCCN), 2008). In fact, the subgroup analysis of a randomised phase II study comparing 5-FU-LV with 5-FU-LV plus bevacizumab suggested that the effect of bevacizumab was particularly beneficial in patients with an Eastern Cooperative Oncology Group (ECOG) PS $>0$, age $>65$ years and albumin $\leqslant 3.5 \mathrm{~g} 100 \mathrm{ml}$ (Fernando and Hurwitz, 2003), characteristics that 
are often observed among the elderly. In addition, in a subsequent randomised phase II study with 5-FU-LV-bevacizumab combination $v s$ 5-FU-LV in patients considered unsuitable for polychemotherapy with irinotecan, a higher overall response rate (ORR; 26 vs 15.3\%, respectively; $P=0.055$ ), higher median progression-free survival (PFS; 9.2 vs 5.5 months, respectively; $P=0.0002)$ and higher overall survival (OS; 16.6 vs 12.9 months, respectively; $P>0.05$ ) were observed for the combination (Kabbinavar et al, 2005).

Capecitabine (Xeloda; Hoffmann-La Roche, Nutley, NJ, USA) is an oral fluoropyrimidine that has efficacy similar to that of 5-FU-LV in bolus as first-line treatment of advanced or metastatic CRC (mCRC; Hoff et al, 2001; Van Cutsem et al, 2001). Results from a previous study by our group suggested that it was also well tolerated in patients over 70 years of age with mCRC, in whom polychemotherapy was not appropriate (Feliu et al, 2005). Even though the addition of bevacizumab to capecitabine may be an interesting therapeutic option for these patients, the data published so far on its efficacy and safety are scarce (Puthillath et al, 2009).

The purpose of this phase II study was to assess the efficacy and safety of a bevacizumab-capecitabine combination in the unfit elderly patient with mCRC.

\section{MATERIALS AND METHODS}

\section{Patient eligibility}

The main inclusion criteria were: histologically confirmed mCRC, age $\geqslant 70$ years, ECOG PS $\leqslant 2$, life expectancy of more than 3 months, $\geqslant 1$ measurable lesion according to the Response Evaluation Criteria in Solid Tumours (RECIST; Therasse et al, 2000) by computed tomography scan and unsuitability for receiving combination with oxaliplatin or irinotecan chemotherapy as per clinical judgment (e.g., patients with $\geqslant 2$ co-morbidities according to the Charlson co-morbidity scale (Charlson et al, 1987) or dependence for any of the basic or instrumental activities of daily living (ADL or IADL); Katz et al, 1963; Lawton, 1988). Patients who were disease free for at least 6 months after completion of adjuvant/neoadjuvant chemotherapy were eligible. Earlier radiotherapy for mCRC was permitted if completed at least 4 weeks before study inclusion and if untreated measurable disease remained. Patients were required to have adequate haematological, hepatic and renal function.

The main exclusion criteria were: operable mCRC before chemotherapy for advanced disease or earlier bevacizumab; CNS metastasis; clinically significant cardiac disease within the past 12 months; lack of physical integrity of the upper gastrointestinal tract or malabsorption syndrome; major surgical procedures or open biopsy, or having experienced significant traumatic injury within 28 days before study entry; serious non-healing wound, ulcer or bone fracture; clinical use of full-dose anti-coagulants or thrombolytics; significant bleeding diathesis or coagulopathy; and proteinuria $\geqslant 500 \mathrm{mg}$ every $24 \mathrm{~h}$.

The study was conducted after approval by the appropriate independent ethics committee of each site and in accordance with the Declaration of Helsinki, Good Clinical Practices and local ethical and legal requirements. All patients provided written informed consent according to local ethics committee regulations.

\section{Treatment plan}

The initial dose of capecitabine was determined according to the patient's renal function (creatinine clearance; $\mathrm{CrCl}$ ). Patients received a capecitabine dose of $1250 \mathrm{mg} \mathrm{m}^{-2}$ twice daily $\left(2500 \mathrm{mg} \mathrm{m}^{-2}\right.$ total daily dose) if their $\mathrm{CrCl}>50 \mathrm{ml} \mathrm{min}^{-1}$ and up to $950 \mathrm{mg} \mathrm{m}^{-2}$ twice daily ( $1900 \mathrm{mg} \mathrm{m}^{-2}$ total daily dose) if they had a $\mathrm{CrCl}$ of $30-50 \mathrm{ml} \mathrm{min}^{-1}$. Capecitabine was administered for 2 weeks, followed by 1 week of rest. Bevacizumab was administered as a 30-90 min intravenous infusion at a dose of $7.5 \mathrm{mg} \mathrm{kg}^{-1}$ on day 1 of a 3-week cycle.

The Cockcroft-Gault formula (Cockcroft and Gault, 1976) was used to calculate $\mathrm{CrCl}$ levels between cycles. If clearance was $<30 \mathrm{ml} \mathrm{min}^{-1}$, treatment was stopped. Cycles were repeated every 3 weeks for a minimum of three per patient, unless disease progression was noted. Patients with a complete response (CR), partial response or stable disease continued receiving chemotherapy until progression or detection of unacceptable adverse events (AEs).

The administration of bevacizumab was permanently discontinued in case of grade $\geqslant 3$ thromboembolic events, grade $\geqslant 3$ bleeding or uncontrolled hypertension. In case of grade $\geqslant 3$ proteinuria, treatment was withheld until proteinuria improved to $<2$ g every $24 \mathrm{~h}$. Dose reductions for grade 2-4 AEs were carried out for capecitabine as previously described (Van Cutsem et al, 2001).

\section{Study assessments}

A screening evaluation was performed at least 3 weeks before the start of treatment, including a complete anamnesis, physical examination, a routine blood analysis (haematology and biochemistry), carcinoembryogenic antigen measurement, electrocardiogram and imaging studies (chest X-ray; CT of chest, abdomen or pelvis; abdominal ultrasound or bone scan as needed), qualitative proteinuria analysis and ECOG PS. The Charlson comorbidity scale (Charlson et al, 1987) and the Katz and Lawton ADL or IADL indices (Katz et al, 1963; Lawton, 1988) were used to assess patients' co-morbid burden and general functional status at baseline. Before each treatment cycle, patients' ECOG PS, vital signs, blood biochemistry and qualitative proteinuria analysis were repeated until final visit.

Tumour response was evaluated radiologically every 9 weeks (three cycles) or sooner if clinically indicated (together with carcinoembryogenic antigen measurement) during therapy, and every 12 weeks during the follow-up period. The same imaging technique was used throughout the study. RECIST v.1.0 response guidelines were used (Therasse et al, 2000) to define all responses after at least 9 weeks of therapy as follows: CR, partial response, stable disease or progressive disease. Disease control was defined as the sum of patients achieving a CR, partial response or stable disease. Confirmation of all responses was required after 4 weeks. Progression-free survival was defined as the time from the date of first treatment cycle to the first documentation of progressive disease or death by any cause. Overall survival was the time elapsing from the date of the first cycle of treatment until death or last known follow-up.

Patients were evaluated for AEs during therapy and until 28 days after the last study drug dose. Adverse events were graded according to the National Cancer Institute Common Toxicity Criteria (NCI CTCAE, version 3.0). For hand-foot syndrome, the previously published grading system was used (Blum et al, 1999).

\section{Statistical methods}

The primary objective was to determine the ORR of the bevacizumab-capecitabine regimen in the intention-to-treat population. Secondary objectives were to analyse the PFS, OS and safety profile of the combination.

An optimal two-stage design as described by Simon (1989) was used. Assuming a minimum efficacy of $15 \%$, we proposed an achievement of a $30 \%$ response rate with the study combination, at a level of significance of $95 \%(\alpha$ error $=0.05)$ and a statistical power of $80 \%$ ( $\beta$ error $=0.20)$. Assuming that $10 \%$ of patients would not be assessable, a total of 59 patients were included. 
As exploratory analyses, a univariate analysis was used to compare the rate of grade $3 / 4$ AEs according to age (70-79 years $v s$ $\geqslant 80$ years $)$, gender, $\mathrm{CrCl}\left(<50 v s \geqslant 50 \mathrm{ml} \mathrm{min}^{-1}\right)$, Charlson co-morbidity scale $(0 v s \geqslant 1)$, ECOG PS $(0 v s \geqslant 1)$ and ADL and IADL (independent $v s$ dependent). Efficacy rates (response rate, PFS and OS) according to the Charlson co-morbidity scale were also compared. Wilcoxon's signed-rank test (to compare quantitative variables) and Fisher's exact test (to compare percentages) were used. The OS and PFS values were calculated using the Kaplan-Meier method.

\section{RESULTS}

\section{Patients' characteristics}

Between August 2006 and January 2008, 59 patients, aged $\geqslant 70$ years, with recurrent or mCRC were enrolled in the study. The patients' characteristics are shown in Table 1 . A total of 22 patients $(37 \%)$ had metastasis at diagnosis. Eight patients (13\%) had two or more co-morbidities.

\section{Treatment exposure}

A total of 416 treatment cycles with a mean ( \pm s.d.) of $7.1( \pm 6.5)$ cycles per patient were administered. All of the patients enrolled in the study received at least one dose of the study medication and were considered evaluable for safety. The mean dose intensity of capecitabine was $14.6 \mathrm{~g} \mathrm{~m}^{-2}$ per week, this being equivalent to $94.2 \%$ of the foreseen dose intensity; it was $7.47 \mathrm{mg} \mathrm{kg}^{-1}$ per cycle for bevacizumab, which is equivalent to $99.02 \%$ of the scheduled dose intensity.

Capecitabine dose reduction/discontinuation was required in 35 (59\%) patients because of AEs, the most frequent being nonhaematological toxicities, principally, hand-foot syndrome and diarrhoea. Other causes included laboratory abnormal values, such as decrease in $\mathrm{CrCl}<30 \mathrm{mg} 100 \mathrm{ml}^{-1}$ and thrombocytopenia/ anaemia. A total of 14 patients (24\%) required at least one bevacizumab dose discontinuation because of AEs, mainly, hypertension, thromboembolism, proteinuria, haemorrhage and weight loss, all with a similar incidence rate.

Reasons for discontinuation of treatment were as follows: disease progression in 25 patients (43\%), AEs in 11 (19\%) patients, death for non-tumour causes in 6 patients $(10 \%)$, patient refusal in $5(9 \%)$, protocol violation in $1(2 \%)$ and other reasons in $10(17 \%)$.

\section{Efficacy}

Out of the 59 patients enrolled in the study, 53 were considered to be evaluable for response. Five patients died and one patient discontinued study treatment because of AEs before completing the first 3 months of treatment and before response had been evaluated. However, they were included in the efficacy analysis as treatment failures in an intention-to-treat analysis (Table 2). Overall response rate was $34 \%(95 \%$ confidence interval, 22.4-47.5\%), including one patient (2\%) with CR and 19 patients (32\%) with partial response. A further 22 patients (37\%) achieved stable disease, giving a disease control rate of $71 \%$. A total of 11 patients (19\%) experienced progressive disease.

Progression-free survival median was 10.8 months (95\% confidence interval, 7.6-14.1 months; Figure 1), median OS was 18 months (95\% confidence interval, 9.6-26.3 months; Figure 2). No correlation between response rate, PFS or OS and co-morbidity at baseline was observed.

A total of 13 patients received second-line chemotherapy after progression, which consisted of oxaliplatin- $(n=7)$ or irinotecan $(n=6)$ with or without cetuximab. All these patients had no
Table I Baseline patient characteristics

\begin{tabular}{|c|c|c|}
\hline Patient characteristics & Median (range) & $n(\%)$ \\
\hline Age (years) & $75(73-79)$ & \\
\hline \multicolumn{3}{|l|}{ Range } \\
\hline $70-74$ & & $27(46)$ \\
\hline $75-79$ & & $19(32)$ \\
\hline$\geqslant 80$ & & $13(22)$ \\
\hline \multicolumn{3}{|l|}{ Gender } \\
\hline Male & & $34(58)$ \\
\hline Female & & $25(42)$ \\
\hline \multicolumn{3}{|l|}{ Previous adjuvant treatment } \\
\hline Chemotherapy & & $7(12)$ \\
\hline Chemotherapy and Radiotherapy & & $4(7)$ \\
\hline Radiotherapy & & I (2) \\
\hline \multicolumn{3}{|l|}{ ECOG PS } \\
\hline 0 & & $26(44)$ \\
\hline I & & $31(53)$ \\
\hline 2 & & $2(3)$ \\
\hline \multicolumn{3}{|l|}{ Primary tumour location } \\
\hline Colon & & $37(63)$ \\
\hline Rectum & & $15(25)$ \\
\hline Rectum and Colon & & $7(12)$ \\
\hline \multicolumn{3}{|l|}{ No. of metastatic sites } \\
\hline 1 & & $32(54)$ \\
\hline 2 & & $22(37)$ \\
\hline$\geqslant 3$ & & $5(9)$ \\
\hline \multicolumn{3}{|l|}{ Localization of the metastases $^{\mathrm{a}}$} \\
\hline Liver & & $50(85)$ \\
\hline Lung & & $27(46)$ \\
\hline Others & & $14(24)$ \\
\hline \multicolumn{3}{|c|}{ Compromised ADL (moderate to total dependence) } \\
\hline Lawton scale (IADL) & & $19(32)$ \\
\hline Barthel scale (ADL) & & $8(14)$ \\
\hline \multicolumn{3}{|l|}{ Co-morbidities } \\
\hline Hypertension & & $36(61)$ \\
\hline Venous thrombosis & & $3(5)$ \\
\hline Cardiac disease & & $3(5)$ \\
\hline Acute cerebrovascular accident history & & $2(3)$ \\
\hline \multicolumn{3}{|l|}{ Charlson co-morbidity scale } \\
\hline 0 & & $22(37)$ \\
\hline I & & $29(50)$ \\
\hline 2 & & $6(10)$ \\
\hline$\geqslant 3$ & & $2(3)$ \\
\hline
\end{tabular}

Abbreviations: ECOG PS = Eastern Cooperative Oncology Group performance status; $A D L=$ activities of daily living; $\mid A D L=$ instrumental activities of daily living. aEach patient may have more than one location.

Table 2 Best response to treatment

\begin{tabular}{lcr}
\hline Response & No. of patients & $\%$ \\
\hline Complete response & 1 & 2 \\
Partial response & 19 & 32 \\
Stable disease & 22 & 37 \\
Progressive disease & 11 & 19 \\
Not evaluable & 6 & 10 \\
\hline
\end{tabular}

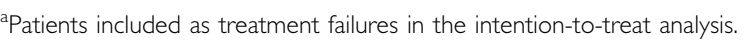

co-morbidities (as per Charlson scale) along with an acceptable IADL and ADL index at baseline, and their tolerability to study treatment was good. 


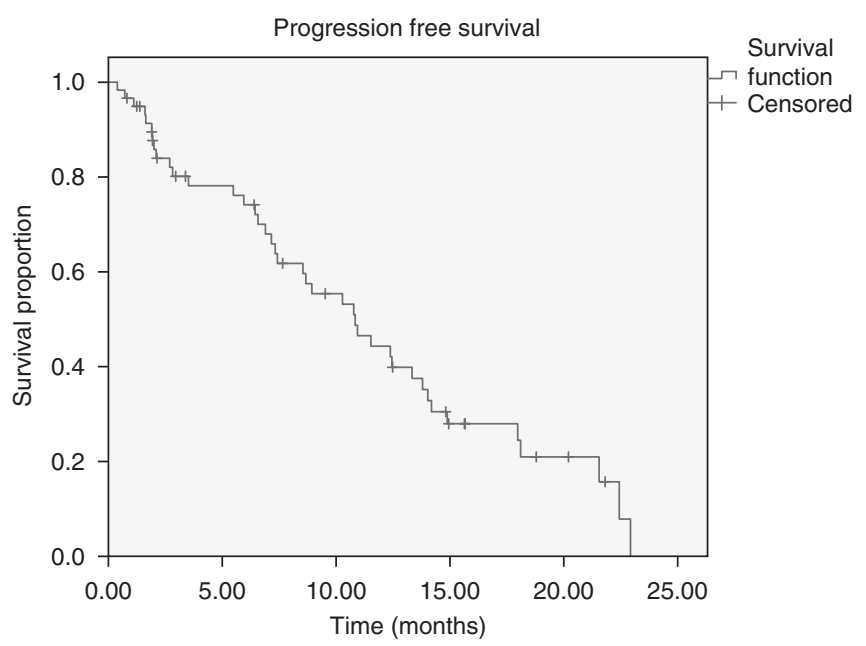

Figure I Progression-free survival.

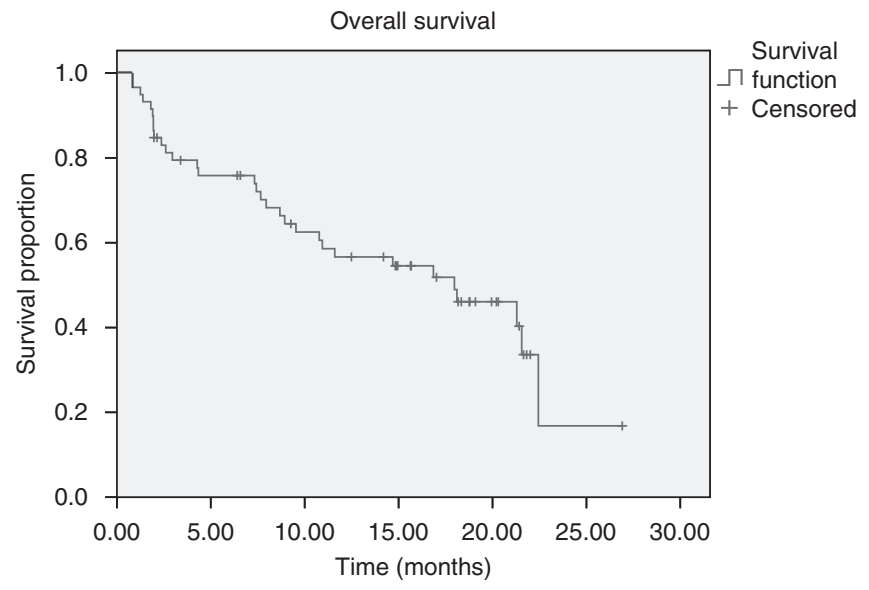

Figure 2 Overall survival.

\section{Safety}

Out of 59 patients, 57 (97\%) reported at least one treatment-related emergent AE. The majority (74\%) of treatment-related AEs were considered to be of grade $1 / 2$. Hand-foot syndrome, diarrhoea, asthenia, pain, mucositis and arterial hypertension were the most frequent $(>20 \%)$ treatment-related AEs reported (Table 3 ). In all, 32 patients (54\%) experienced grade $3 / 4$ AEs, the most common being hand-foot syndrome (19\%) and diarrhoea (9\%). A total of $12(20 \%)$ patients experienced treatment-related arterial hypertension, this being grade 3 in one patient (2\%). Furthermore, four (7\%) patients had grade 3 treatment-related deep venous thrombosis and two (3\%) patients had grade 1 epistaxis. No arterial thrombotic events (acute myocardial infarction, acute cerebrovascular accident or peripheral arterial thrombosis) were reported. Nine patients $(15 \%)$ died within the first 60 days of the study: four (7\%) were due to progressive disease and five died as a result of toxicity, which was considered treatment related in four (mucositis, digestive haemorrhage, haematologic toxicity and sepsis).

No correlation between the development of grade 3/4 AEs and age, ECOG, co-morbidity, IADL and ADL at baseline was observed. A higher frequency of bevacizumab-non-related (excluding hypertension, bleeding, proteinuria and arterial or venous thrombotic phenomena) grade $3 / 4$ AEs was noted in those cycles in which $\mathrm{CrCl}$ was $\leqslant 50 \mathrm{ml} \mathrm{min}^{-1}$ (23 vs $\left.13 \% ; P<0.05\right)$.
Table 3 Most common ( $\geqslant 5 \%)$ treatment-related AEs per patient

\begin{tabular}{lcc}
\hline NCI-CTCAE toxicity & $\begin{array}{c}\text { Grade I//2 } \\
\mathbf{n}(\%)\end{array}$ & $\begin{array}{c}\text { Grade } \mathbf{3 / 4} \\
\mathbf{n}(\%)\end{array}$ \\
\hline Hand-foot syndrome & $16(27)$ & $11(19)$ \\
Diarrhoea & $21(36)$ & $5(9)$ \\
Asthenia & $18(31)$ & $2(3)$ \\
Pain & $10(17)$ & $3(5)$ \\
Mucositis & $11(19)$ & $2(3)$ \\
Arterial hypertension & $11(19)$ & $1(2)$ \\
Thrombocytopenia & $5(9)$ & $2(3)$ \\
Anorexia & $6(10)$ & $1(2)$ \\
Vomiting & $6(10)$ & - \\
Nausea & $6(10)$ & $1(2)$ \\
Anaemia & $4(7)$ & $4(7)$ \\
Deep venous thrombosis & - & $2(3)$ \\
Neutropenia & $1(2)$ & - \\
Abdominal pain & $3(5)$ & - \\
Infection & $3(5)$ & - \\
\hline
\end{tabular}

Abbreviations: $\mathrm{AE}=$ adverse event; $\mathrm{NCl}-\mathrm{CTCAE}=$ National Cancer institute Common Toxicity Criteria.

Furthermore, the $\mathrm{CrCl}$ mean value was significantly lower in cycles in which a grade $3 / 4 \mathrm{AE}$ was reported than in cycles not reporting this AE grade (55 vs $62 \mathrm{ml} \mathrm{min}^{-1}$, respectively; $P<0.05$ ).

\section{DISCUSSION}

This is the first complete phase II study that analyses the efficacy and tolerability of bevacizumab combined with capecitabine chemotherapy in the elderly with mCRC. The efficacy of this regimen was noteworthy, with a $34 \%$ ORR, a disease control achievement in $71 \%$ of the patients and a median PFS and median OS of 10.8 and 18 months, respectively. These results seem to be better than those reported with the 5-FU-LV-bevacizumab regimen (ORR 26\%, median PFS: 9.2 months and median OS: 16.6 months; Kabbinavar et al, 2005). Furthermore, they substantiate the results of a recent underpowered study by Puthillath et al, (2009) in 16 elderly subjects with mCRC treated with biweekly bevacizumab-capecitabine, in which a $25 \%$ ORR, a median PFS of 9.5 months and a median OS of 21 months were achieved. It should be noted that a $24 \%$ ORR and a median PFS of 7 months were achieved in a previous study conducted by our group in elderly subjects treated with capecitabine monotherapy (Feliu et al, 2005). Thus, bearing in mind the need for caution when results from different studies are compared, the current results support the beneficial effect of adding bevacizumab to firstline chemotherapy or capecitabine monotherapy for mCRC.

These results should be considered within the context of the elderly population studied and should be extrapolated with caution to the unfit geriatric population not included in clinical trials. In our study, a specific criterion to be eligible was the unsuitability to receive polychemotherapy because of the greater susceptibility of this patient population to treatment-related AEs. In fact, our patients often had some form of associated co-morbidity or a suboptimal IADL or ADL score. Nevertheless, there were also a number of patients not fulfilling any of these characteristics included, as they were not considered to be optimal for polychemotherapy merely on the basis of physician's subjective criteria. Furthermore, although unsuitability for receiving combination chemotherapy was an inclusion criterion, a few patients received these agents as second-line treatment according to clinician judgment in view of their good co-morbidity status at baseline and their good tolerability to the study drugs. Similar to other authors (Kabbinavar et al, 2005), we consider that these patients, despite their unfavourable characteristics, may benefit 
from less-aggressive therapeutic alternatives. In this respect, a recent phase III randomised study (Tebbutt et al, 2009) in relatively elderly patients with unresecable mCRC previously untreated also found that the addition of bevacizumab to capecitabine significantly improved PFS without either significant toxicity or impairment in their quality of life.

Overall, the toxicity observed with the bevacizumab-capecitabine combination in the current study was acceptable, with handfoot syndrome and diarrhoea being the most commonly reported related AEs. Although up to $54 \%$ of the patients reported grade $3 / 4$ AEs, this percentage was much lower than the $87 \%$ reported with the 5-FU-LV-bevacizumab regimen in a population of patients with similar characteristics (Kabbinavar et al, 2005). This is probably due to the lower rate of grade $3 / 4$ diarrhoea observed in our study (9\%) compared with that reported by (39\%). Hand-food syndrome, which may be of special importance in this patient population as it may contribute to falls in the elderly, was reported by $46 \%$ patients in our study, and was rated grade $3 / 4$ in $19 \%$ of patients. The frequency of these AEs was similar to that reported in another study with the same bevacizumab-capecitabine regimen in patients with advanced breast cancer (Miller et al, 2005). With regard to bevacizumab-associated AEs, even though $61 \%$ of patients had been previously diagnosed with hypertension, only one $(3 \%)$ reported treatment-related grade 3 hypertension. No grade 4 hypertension was reported. The proportion of patients who developed grade 3 deep venous thrombosis (7\%) did not differ from that reported in other studies (Kabbinavar et al, 2005; Miller et al, 2005). Although age $\geqslant 65$ years and a history of arteriosclerosis are risk factors for arterial thromboembolic events during treatment with bevacizumab (Scappaticci et al, 2007), this type of event was not reported in our study. Thus, age alone should not preclude patients with $\mathrm{mCRC}$ from receiving bevacizumab-containing therapy, and the risk-benefit balance must be weighted carefully for each patient individually. In fact, in a retrospective analysis of pooled cohorts of older patients from two studies on bevacizumab in mCRC, the risks for bevacizumab-associated events did not seem to be greater than those seen in younger patients (Kabbinavar et al, 2009). Moreover, the benefit derived by older patients with mCRC on adding bevacizumab to first-line chemotherapy was similar to that of younger patients without substantial increase in toxicity, according to the results of the bevacizumab Expanded Access Trial (BEAT; Van Cutsem et al, 2009).

A relationship was found between renal function before the administration of each chemotherapy cycle and subsequent

\section{REFERENCES}

Blum JL, Jones SE, Buzdar AU, LoRusso PM, Kuter I, Vogel C, Osterwalder B, Burger HU, Brown CS, Griffin T (1999) Multicenter phase II study of capecitabine in paclitaxel-refractory metastatic breast cancer. J Clin Oncol 17: 485-493

Charlson ME, Pompei P, Ales KL, MacKenzie CR (1987) A new method of classifying prognostic comorbidity in longitudinal studies: development and validation. J Chronic Dis 40: 373-383

Cockcroft DW, Gault MH (1976) Prediction of creatinine clearance from serum creatinine. Nephron 16: $31-41$

Feliu J, Escudero P, Llosa F, Bolanos M, Vicent JM, Yubero A, Sanz-Lacalle JJ, Lopez R, Lopez-Gomez L, Casado E, Gomez-Reina MJ, Gonzalez-Baron M (2005) Capecitabine as first-line treatment for patients older than 70 years with metastatic colorectal cancer: an oncopaz cooperative group study. J Clin Oncol 23: 3104-3111

Fernando NH, Hurwitz HI (2003) Inhibition of vascular endothelial growth factor in the treatment of colorectal cancer. Semin Oncol 30: 39-50

Gatta G, Faivre J, Capocaccia R, Ponz de LM (1998) Survival of colorectal cancer patients in Europe during the period 1978 - 1989. Eur J Cancer 34: $2176-2183$

Hoff PM, Ansari R, Batist G, Cox J, Kocha W, Kuperminc M, Maroun J, Walde D, Weaver C, Harrison E, Burger HU, Osterwalder B, Wong AO, reporting of grade 3/4 AEs. Thus, caution should be exercised in this group of vulnerable elderly subjects regarding their renal function, and $\mathrm{CrCl}$ should be calculated before each chemotherapy cycle. Furthermore, administration of capecitabine in elderly patients with $\mathrm{CrCl} \leqslant 50 \mathrm{ml} \mathrm{min}^{-1}$ should be considered on an individualised basis, as there is a greater risk of AEs (23\% grade $3 / 4$ AEs), even though the dose is reduced according to the common recommendations. In addition, clear instructions must be provided both to the patient and to his/her caregiver on the management of acute AEs, such as diarrhoea, mucositis or fever through regular telephone contact with their doctor or nurse.

Recently, results of some randomised studies in mCRC point to a similar survival rate irrespective of whether a first-line polychemotherapy is used in the first instance and treatment is changed to monotherapy after progression, or monotherapy (e.g., 5-FU or capecitabine) is used in the first instance, followed by polychemotherapy on progression (Koopman et al, 2007; Seymour et al, 2007a,b). In reality, no significant differences between the different chemotherapy regimens (5-FU plus oxaliplatin, capecitabine plus oxaliplatin, 5-FU-LV monotherapy or capecitabine monotherapy) were detected in PFS or in OS in a recent study (FOCUS 2) conducted in 466 elderly or frail patients with $\mathrm{mCRC}$, despite the greater response rate observed with polychemotherapy than with monotherapy (42 vs 39\% vs 15 vs $15 \%$, respectively; Seymour et al, 2007a,b). Thus, when palliative treatment is the objective, it is reasonable to begin with monotherapy and then to consider a second line of polychemotherapy after progression. In that respect, the bevacizumabcapecitabine combination might be an interesting option in selected patients.

In conclusion, our results suggest that elderly patients with some vulnerability criterion (prefrail) unsuitable for receiving first-line polychemotherapy may benefit from bevacizumab in combination with capecitabine with an acceptable toxicity profile. Nevertheless, the most suitable therapeutic regimen for this group of patients is still pending and future studies particularly designed for this elderly population are needed.

\section{ACKNOWLEDGEMENTS}

This study was supported by Hoffmann-La Roche, Nutley, NJ, USA.

Wong R (2001) Comparison of oral capecitabine versus intravenous fluorouracil plus leucovorin as first-line treatment in 605 patients with metastatic colorectal cancer: results of a randomized phase III study. J Clin Oncol 19: 2282-2292

Kabbinavar FF, Hurwitz HI, Yi J, Sarkar S, Rosen O (2009) Addition of bevacizumab to fluorouracil-based first-line treatment of metastatic colorectal cancer: pooled analysis of cohorts of older patients from two randomized clinical trials. J Clin Oncol 27: 199-205

Kabbinavar FF, Schulz J, McCleod M, Patel T, Hamm JT, Hecht JR, Mass R, Perrou B, Nelson B, Novotny WF (2005) Addition of bevacizumab to bolus fluorouracil and leucovorin in first-line metastatic colorectal cancer: results of a randomized phase II trial. J Clin Oncol 23: 3697 - 3705

Katz S, Ford AB, Moskowitz RW, Jackson BA, Jaffe MW (1963) Studies of illness in the aged. The index of ADL: a standardized measure of biological and psychosocial function. JAMA 185: $914-919$

Kohne CH, Folprecht G, Goldberg RM, Mitry E, Rougier P (2008) Chemotherapy in elderly patients with colorectal cancer. Oncologist 13: 390- 402

Koopman M, Antonini NF, Douma J, Wals J, Honkoop AH, Erdkamp FL, de Jong RS, Rodenburg CJ, Vreugdenhil G, Loosveld OJ, van BA, Sinnige HA, Creemers GJ, Tesselaar ME, Slee PH, Werter MJ, Mol L, 
Dalesio O, Punt CJ (2007) Sequential versus combination chemotherapy with capecitabine, irinotecan, and oxaliplatin in advanced colorectal cancer (CAIRO): a phase III randomised controlled trial. Lancet 370: 135-142

Lawton MP (1988) Scales to measure competence in everyday activities. Psychopharmacol Bull 24: 609-614

Miller KD, Chap LI, Holmes FA, Cobleigh MA, Marcom PK, Fehrenbacher L, Dickler M, Overmoyer BA, Reimann JD, Sing AP, Langmuir V, Rugo HS (2005) Randomized phase III trial of capecitabine compared with bevacizumab plus capecitabine in patients with previously treated metastatic breast cancer. J Clin Oncol 23: 792 - 799

National Comprehensive Cancer Network (NCCN) (2008) NCCN Clinical Practice Guidelines in Oncology. Colon Cancer, v.2. http://www.nccn.org (Last accessed: January 13, 2010)

Parkin DM, Bray F, Ferlay J, Pisani P (2005) Global cancer statistics, 2002. CA Cancer J Clin 55: 74-108

Puthillath A, Mashtare Jr T, Wilding G, Khushalani N, Steinbrenner L, Ross ME, Romano K, Wisniewski M, Fakih MG (2009) A phase II study of first-line biweekly capecitabine and bevacizumab in elderly patients with metastatic colorectal cancer. Crit Rev Oncol Hematol 71: 242 - 248

Ries L, Eisner M, Kosary C (2002) SEER Cancer Statistics Review, 1973 - 1999. National Cancer Institute: Bethesda, MD; http://seer.cancer. gov/csr/1973_1999/esoph.pdf (Last accessed: January 13, 2010)

Scappaticci FA, Skillings JR, Holden SN, Gerber HP, Miller K, Kabbinavar F, Bergsland E, Ngai J, Holmgren E, Wang J, Hurwitz H (2007) Arterial thromboembolic events in patients with metastatic carcinoma treated with chemotherapy and bevacizumab. J Natl Cancer Inst 99: $1232-1239$

Seymour MT, Maughan TS, Wasan HS (2007a) Capecitabine (Cap) and oxaliplatin $(\mathrm{Ox})$ in elderly and/or frail patients with metastatic colorectal cancer: The FOCUS2 trial. Proc Am Soc Clin Oncol 25: 9030. (Abstract)
Seymour MT, Maughan TS, Ledermann JA, Topham C, James R, Gwyther SJ, Smith DB, Shepherd S, Maraveyas A, Ferry DR, Meade AM, Thompson L, Griffiths GO, Parmar MK, Stephens RJ (2007b) Different strategies of sequential and combination chemotherapy for patients with poor prognosis advanced colorectal cancer (MRC FOCUS): a randomised controlled trial. Lancet 370: $143-152$

Simon R (1989) Optimal two-stage designs for phase II clinical trials. Control Clin Trials 10: $1-10$

Tebbutt NC, Gebski V, Wilson M (2009) International randomized phase III study of capecitabine, bevacizumab and mitomycin C (MMC) in first line treatment for metastatic colorectal cancer: final results of the AGITG MAX trial. J Clin Oncol 27: 4023 (Abstract)

Therasse P, Arbuck SG, Eisenhauer EA, Wanders J, Kaplan RS, Rubinstein L, Verweij J, Van GM, van Oosterom AT, Christian MC, Gwyther SG (2000) New guidelines to evaluate the response to treatment in solid tumors. European Organization for Research and Treatment of Cancer, National Cancer Institute of the United States, National Cancer Institute of Canada. J Natl Cancer Inst 92: 205-216

Van Cutsem E, Rivera F, Berry S (2009) Safety and efficacy of bevacizumab and chemotherapy in elderly patients with metastatic colorectal cancer: Results from the bevacizumab expanded access trial (BEAT). ECCO 15-34th ESMO Multidisciplinary Congress: Berlin, Germany, pp 20-24 September (Abstract)

Van Cutsem E., Twelves C, Cassidy J, Allman D, Bajetta E, Boyer M, Bugat R, Findlay M, Frings S, Jahn M, McKendrick J, Osterwalder B, PerezManga G, Rosso R, Rougier P, Schmiegel WH, Seitz JF, Thompson P, Vieitez JM, Weitzel C, Harper P (2001) Oral capecitabine compared with intravenous fluorouracil plus leucovorin in patients with metastatic colorectal cancer: results of a large phase III study. J Clin Oncol 19: 4097-4106 